\title{
Cournot versus Supply Functions: What does the data tell us? ${ }^{1}$
}

\author{
Bert WILLEMS \\ Tilburg University, TILEC \& CentER \\ K.U.Leuven, Energy Institute \& CES \\ b.r.r.willems@uvt.nl \\ Ina RUMIANTSEVA \\ Hannes WEIGT \\ Dresden University of Technology, Faculty of Business and Economics \\ Chair of Energy Economics and Public Sector Management \\ ina.rumiantseva@mailbox.tu-dresden.de \\ hannes.weigt@tu-dresden.de
}

\begin{abstract}
The liberalization of the electricity sector increases the need for realistic and robust models of the oligopolistic interaction of electricity firms. This paper compares the two most popular models: Cournot and the Supply Function Equilibrium (SFE), and tests which model describes the observed market data best. Using identical demand and supply specifications, both models are calibrated to the German electricity market by varying the contract cover of firms. Our results show that each model explains an identical fraction of the observed price variation. We therefore suggest using Cournot models for short term analysis, as more market details, such as network constraints, can be accommodated. As the SFE model is less sensitive to the choice of the calibration parameters, it might be more appropriate for long term analysis, such as the study of a merger.
\end{abstract}

JEL: L94, L13, C72, D43

Keywords: supply function equilibrium, Cournot competition, electricity markets

\footnotetext{
${ }^{1}$ We thank Lapo Filistrucchi, Karsten Neuhoff and Christian von Hirschhausen for their comments and suggestions.
} 


\section{Introduction}

Within the last two decades electricity markets have undergone significant structural changes due to liberalization processes. In the course of this development the need for market analyses has emerged. Market analysis is a complex task as the decentralized structure of liberalized electricity markets increases interaction between market players, and as regulatory guidelines, market design and the specific technical characteristics of electricity have to be taken into account. The need of regulators and politicians to determine market outcomes but also the interest of market players in simulating expected market situations has fostered the development of modeling approaches. Besides technical models needed to determine power plant schedules or network conditions, market models that can cope with strategic behavior are essential.

Classical economic tools, such as the Herfindahl-Hirschman Index (HHI), are largely unsuitable for electricity markets and specific tools and models have to be designed (Borenstein, et al. 1999). ${ }^{2}$ In their survey on electricity market models, Ventosa et al. (2005) identify three basic trends: optimization models, equilibrium models and simulation models. This paper will focus on two equilibrium models for oligopolisic wholesale electricity markets: the Cournot model and the Supply Function Equilibrium model (SFE). We will compare both models, and examine which is more suited to model strategic behavior.

While standard Cournot models are easy to calculate, the results often do not represent reasonable market outcomes. Given demand elasticities that are realistic for the electricity sector, prices are too high, and output too low. In Cournot models for electricity markets, it is therefore often assumed that a fixed percentage of sales is covered by forward contracts. ${ }^{3}$ This coverage factor is then used as a calibration parameter of the model. By adjusting the coverage factor one finds an infinite set of equilibria, ranging from perfect competition to standard Cournot outcomes. Ellersdorfer (2005) shows this for the example of Germany.

Supply Function Equilibria (Klemperer and Meyer, 1989) on the other hand are considered to represent electricity markets in a more realistic way than Cournot models. They assume that generators compete by bidding continuous and smooth functions in an oligopolistic market with

${ }^{2}$ An overview about the basic characteristics and economic analysis tools suitable for electricity markets can be found in Twomey et al. (2005).

${ }^{3}$ Alternatively one could also assume that generators are vertically integrated with the retail sector for part of their activities. 
demand uncertainty. The SFE approach has been used in several applications to analyze electricity market since its first application by Green and Newbery (1992) for England and Wales. The main drawbacks of the supply function models is that they are difficult to calculate, have often multiple equilibria, might have unstable solutions, and require strong simplifications with respect to market and cost structures.

The aim of this paper is to compare two modeling approaches, the Cournot model with forward contracting and the Supply Function Equilibrium (SFE) model. It shall be tested whether they give similar predictions, and whether the range of feasible equilibrium outcomes is similar. We check in how far the added complexity of SFE models is offset by more robust and more realistic predictions. This is done by calibrating the two models with an identical data set of the German electricity market, and by comparing the modeling results with the market clearing prices.

The remainder of the paper is structured as follows. In the next section an overview about the theory of SFE and Cournot modeling is given. Section 3 describes the implementation of the model and the underlying assumptions. In section 4 a data set for the German market and the model calibration method are presented. Section 5 presents and discusses the simulation results, while section 6 closes with a summary and conclusions.

\section{Theoretic Background on SFE and Cournot}

With Cournot and SFE models, two major trends have emerged to analyze oligopolistic electricity market outcomes, in particular wholesale markets. ${ }^{4}$ Both approaches assume profit maximizing companies but differ in the assumption regarding the free choice variables and the behavior of the remaining market participants. The profit function in general is composed of the revenue minus generation costs:

$$
p\left(q_{i}+q_{-i}\right) q_{i}-c\left(q_{i}\right)
$$

The classic Cournot models assume each firm to maximize profits by setting production quantities and sales $q_{i}$ assuming that the output of other companies $q_{-i}$ does not depend on its output decisions. The Cournot approach yields a direct outcome in terms of price and quantities as a function of the demand function $p(q)$. Cournot models are easy to solve and provide, under the right conditions a unique Nash equilibrium.

\footnotetext{
${ }^{4}$ Another classic approach to model oligopolistic markets is the Bertrand model. As this is seldom used in electricity markets we do not consider it in detail.
} 
In the SFE models (Klemperer and Meyer, 1989), each firm maximizes profits by bidding a supply curve $q_{i}(p)$, assuming that the supply function of the other players $q_{-i}(p)$ remains fixed. Hence, the quantity that a firm's competitors will produce depend on the market price and thus indirectly on the output decision of the firm itself. Demand is assumed to be random and to shift horizontally. Under these assumptions the (stochastic) optimization problem that each firm needs to solve can be rewritten as a differential equation. Solving a set of differential equations, one for each firm, typically a range of feasible equilibrium supply functions is found. It can be shown that every SFE supply function lies between the Cournot and the Bertrand solution for any realized demand shock. Delgado and Moreno (2004) show, however, that only the leastcompetitive equilibrium is coalition proof when the number of firms is sufficiently large. SFE models face drawbacks regarding their solvability as they require simplified assumptions of the markets supply structure to obtain feasibly solutions. ${ }^{5}$

\subsection{Use of Cournot and SFE models in electricity markets}

Both the SFE model and the Cournot model have been used extensively to model electricity markets. In this subsection an overview of the usage of both models is given.

SFE models are often used for market power analyses in electricity markets. Bolle (1992) makes a theoretical application to electricity markets by analyzing the possibility of tacit collusion when bidding in supply functions. He concludes that if firms coordinate on bidding the highest feasible supply function, a decrease in market concentration does not necessarily result in convergence of aggregated profits to zero. Green and Newbery (1992) present an empirical analysis for England and Wales using symmetric players. They compare the duopoly of National Power and PowerGen with a hypothetical five firm oligopoly concluding that this results in a range of supply functions closer to marginal costs.

Baldick and Hogan (2002) set up another model of the England and Wales market including capacity constraints of the strategic firms. They incorporate price caps, capacity constraints, and vary the time horizon that supply functions have to remain fixed. They show that particularly the latter has a large impact on market competitiveness. Evans and Green (2005) simulated the same market for the period of April 1997 to March 2004 assuming linear marginal cost functions to determine linear supply functions of asymmetric firms. They conclude that the change from a centralized to a decentralized market has no impact on short term electricity prices whereas the

\footnotetext{
${ }^{5}$ A detailed presentation of the SFE approach is given in Klemperer and Meyer (1989).
} 
reduction in concentration has. Sioshansi and Oren (1997) study the Texas balancing market using supply function equilibria with capacity constraints. They find that the larger firms more or less behave according to the SFE equilibrium for incremental bids. They argue that SFE models with capacity constraints are an interesting tool to study balancing markets as demand is very inelastic in these markets, and hence the supply elasticity of competitors is a major component in determining the elasticity of the residual demand of the firms. These SFE models with capacity constraints are also interesting because they reflect the actual bidding behavior of the firms, i.e. hockey stick bidding: they bid (too) low for low levels of supply and have a steep supply function for larger levels of supply.

Besides empirical analyses with SFE, several theoretical contributions have extended Klemperer and Meyer (1992) incorporating typical market characteristics. Holmberg (2005) considers the problem of asymmetric companies by simplifying the supply structure to constant marginal costs. He shows that under this setup there is a unique SFE, which is piece-wise symmetric. Anderson and $\mathrm{Hu}$ (2005) also consider asymmetric market structures and propose a numerical approach using piecewise linear supply functions and a discretization of the demand distribution. They show that the approach has good convergence behavior also in models with capacity constraints. Holmberg (2006) studies capacity constraints on generation units and shows that with symmetric producers, inelastic demand, price cap, and capacity constraints there exists a unique, symmetric SFE. Green (1996), Rudkevich (2005) and Baldick, et al (2004) develop the theory of linear supply functions. These linear supply functions are easier to solve, can also be used in asymmetric games, and generally give stable and unique equilibria. Their main drawback is that they do not take capacity constraints into account. Boisseleau et al. (2004) use a piece-wise linear supply function and describe a solution algorithm which obtains an equilibrium even when there are capacity constraints.

In applied studies on electricity markets Cournot models are ubiquitous and are applied to a wide range of applications. One drawback of Cournot models is that they often overestimate observed market prices and underestimate market quantities. As the model outcome is solely based on quantity competition the results are highly sensitive to assumptions on demand elasticity: In equilibrium, firm $i$ sets its output such that its markup is proportional to its market share $s_{i}$ and inverse proportional to the demand elasticity $\varepsilon$ of the total market.

$$
\frac{P-C_{i}^{\prime}}{P}=\frac{s_{i}}{\varepsilon}
$$


Given that most electricity markets have few oligopolistic firms ( $S_{i}$ is large) and a low short-term demand elasticities, markups are accordingly very high.

Following Allaz and Villa (1993) forward contracts can be used to predict more realistic market outcomes. ${ }^{6}$ Firms not only sell energy in a spot market but can also sell a certain amount of their supply forward. In a two stage game the oligopolists first decide about the forward quantity before entering the spot market and playing a Cournot game. Thus forward sales reduce the oligopolists' available quantity in the spot market, resulting in a more competitive market. When using a single stage game, the impact of forward contracts can be simulated by taking into account the contract volume $F_{i}$ in the profit function:

$$
p\left(q_{i}+q_{-i}\right)\left(q_{i}-F_{i}\right)-c\left(q_{i}\right)
$$

This results in a reduced markup on marginal costs as the contracting factor $f_{i}=F_{i} / q_{i}$ has to be considered:

$$
\frac{P-C_{i}^{\prime}}{P}=\frac{s_{i}}{\varepsilon}\left(1-f_{i}\right)
$$

By varying the contacting factor a bundle of feasible Cournot solutions can be generated resembling SFE outcomes.

The role of forward contracts when comparing Cournot results with real market outcomes is clearly demonstrated by Bushnell et al. (2005). They look at California, PJM and New England markets and compare price data of the power exchanges with competitive model outcomes, a standard Cournot model and a Cournot model with contract cover as approximation for vertical arrangements. They conclude that neglecting the contract cover yields results that vastly exceed observed market prices. Ellersdorfer (2005) analyses the competitiveness of the German electricity market using a multi-regional two-stage Cournot model. He shows to what extent cross border network extensions and increased forward capacities enhance competition and decrease market power.

Cournot approaches are often preferred when technical characteristics such as network constraints (voltage stability, loop flows) or generation characteristics, (start-up costs, ramping constraints, unit commitment) have to be taken into account. Particularly the impact of congestion on market prices and market power has been analyzed in several studies. Smeers and Wei (1997) use

\footnotetext{
${ }^{6}$ One further alternative to predict more realistic market outcomes is the conjectural variation approach, which is not considered within this paper.
} 
variational inequalities to describe the Cournot model. Willems (2002) discusses the necessary assumptions to include transmission constraints in Cournot models. Neuhoff et al. (2005) summarize different characteristics of Cournot network models. They show that although all models predict the same outcomes in case of competitive markets they vary with respect to assumptions about market design and expectations of generators.

A more general overview of Cournot models used to analyze market power issues can be found in Bushnell et al. (1999). Further reviews of electricity market models also with respect to network issues are given in Day et al. (2002) and Ventosa et al. (2005).

\subsection{Comparing Cournot and SFE-models}

Only a few authors have compared the equilibria in Cournot models and SFE models. Related to our paper, is the work by Xavier Vives (2007). Vives compares the properties of two auction mechanisms, one where firms bid supply functions and one where they bid a la Cournot. Firms are assumed to have private information about their uncertain costs. Solving for a linear Baysian equilibrium, Vives shows that supply functions aggregate the dispersed information of the players, while the Cournot model does not. Hence, Cournot games might be socially less efficient, as dispersed information is not used efficiently. Our paper is different as we are less interested in understanding the properties of different auction mechanisms. In our model, firms have perfect information about their costs, firms have contracted capacity forward, and supply functions are not restricted to linear bid functions.

Hu et al. (2004) use a bilevel game to model markets for delivery of electrical power on looped transmission networks with the focus on the function of an ISO. Within this analysis they compare supply function and Cournot equilibria and show that in case of transmission congestion SFE need not to be bounded from above by Cournot equilibria as is the case for unconstrained networks. They conclude that in the presence of congestion, Cournot games may be more efficient than supply function bidding.

Ciarreta and Gutiérrez-Hita (2006) make a theoretical analysis of collusion in repeated oligopoly games, using a supergame model that is designed both for supply function and quantity competition. They show that depending on the number of rivals and the slope of the market demand, collusion is easier to sustain under supply function rather than under quantity competition. An experimental approach by Brandts, Pezanis-Christou and Schram (2003) includes the impact of forward contracts on electricity market outcomes with differences due to Cournot and supply function competition. They show that the theoretical outcomes of SFE models, mainly their feasibility range between Cournot and marginal costs, can be reproduced by 
experimental economics. Furthermore they find that for both types of competition the introduction of a forward market significantly lowers prices.

\section{Model formulation}

The supply function model and the Cournot model are found by simultaneously solving a set of equations describing the market equilibrium for different demand realizations $k$. In order to compare the two results of the models, we will use identical assumptions with respect to the demand and supply structure of the market: the market demand is assumed to be linear whereas the supply curve is a cubic function based on the actual power plant costs (see section 4).

The demand equation describes how the demand $D^{o}$ that strategic players (oligopolies) face in period $k$, depends on the demand shock $\Delta_{k}$ and the price $p_{k}$ in that period:

$$
D_{k}^{O}=\alpha-\gamma \cdot p_{k}-\Delta_{k}
$$

The energy balance equation describes that for all demand realizations $k$, demand should equal supply by the oligopolists:

$$
D_{k}^{O}=S_{k}^{O}
$$

where $S_{k}^{O}=\sum_{i=1}^{4} q_{i k}$

The marginal cost equation relates output of firm $i$ with the marginal cost of that production plant:

$$
c_{k, i}=\sum_{n=0}^{3} \lambda_{n, i} q_{k, i}{ }^{n}
$$

The continuity equation imposes continuity of the supply function. It describes the relation between the slope of the supply function $\beta$, the production levels, and the price level of the firms. Continuity implies that the arc-slope of the supply function can be written as the weighted sum of the slopes at the two end points of the interval. In other words, we find that

$$
q_{i, k+1}-q_{i, k}=\left(p_{k+1}-p_{k}\right)\left[\left(1-\xi_{i k}\right) \beta_{i k}+\xi_{i k} \beta_{i k+1}\right]
$$

with $0<\xi_{i k}<1$. This formulation is due to Anderson and $\mathrm{Hu}$ (2005).

The pricing equation describes the first order conditions of each player $i$ for each demand shock $k$. It requires that the marginal revenue of the player is equal to its marginal cost.

$$
\left(q_{i k}-F_{i k}\right) \frac{d p_{i k}^{R}}{d q_{i k}}=p_{k}-c_{i k}
$$


$F_{i k}$ is the amount of contracts which is signed in equilibrium by firm $i$ in period $k$. We allow the firms to sign different type of contracts: fixed capacity contracts and load-following contracts. A fixed contract specifies a quantity (in MW) which is independent on the demand shock $k$ : $F_{i k}=f_{k}$. A typical fixed contract would be a base-load contract where the firm commits to sell forward a fixed amount of energy. A load-following contract is a contract where for each realization of the demand shock a certain fraction of the sales is contracted forward: $F_{i k}=\phi_{i} q_{i k}$ The pricing equation is different for the supply function equilibrium and for the Cournot model: In the Cournot equilibrium, each player assumes the production of the other players as given, and therefore the slope of the residual inverse demand function depends only on the slope of the demand function $(1 / \gamma)$. We assume that the players have signed a combination of fixed and loadfollowing contracts:

$$
F_{i k}=f_{i}+\phi_{i}\left(q_{i k}-f_{i}\right)
$$

Firm $i$ signs $f_{i}$ fixed contracts, and sells a certain percentage of the remaining sales forward. For the Cournot equilibrium, the pricing equation becomes:

$$
q_{i k}-f_{i}=\left(p_{k}-c_{i k}\right) \gamma\left(1-\phi_{i}\right)^{-1}
$$

With the supply function equilibrium, the slope of the residual demand function depends on the slope of the demand function and the slope of the supply functions of the competitors. For the SFE model, we assume that the firms do only sign fixed contracts $F_{i k}=f_{i}$, and the pricing equation becomes:

$$
q_{i k}-f_{i}=\left(p_{k}-c_{i k}\right)\left(\sum_{j \neq i} \beta_{j k}+\gamma\right)
$$

A Cournot equilibrium is a solution of equation (5), (6). (7) and (11). A supply function equilibrium is a solution of equation (5), (6), (7), (8) and (12). The equilibrium is described as the price and demand level for shock $k, D_{k}, p_{k}$ and for each firm $i$ a description of production, marginal costs and a slope of the demand function $\beta_{i k}, q_{i k}, c_{i k}$. The solution of these equations is not straightforward given to the non-linearities in equations (12) and (8).

The model is solved using the COIN-IPOPT solver in GAMS (Wächter and Biegler, 2006). ${ }^{7}$

\footnotetext{
7 The Conopt solver which was used by Anderson and Hu (2005) did not always converge. Hence our results confirm Sioshansi and Oren (1997), who mention similar problems with CONOPT solver in a setting with capacity constraints.
} 


\section{Data}

We use data of the German electricity market including generation, imports and demand. We chose to study the German market as it has an oligopolistic structure, which is the type of market that Cournot and SFE models should be able to represent: the German market consist of two large firms (E.ON and RWE) owning about 50\% of generation capacity, two smaller firms (Vattenfall and $\mathrm{EnBW}$ ) with each about $15 \%$ of the market, and a competitive fringe acting as a price-taker. The German electricity system is a winter peaking system with a large share of nuclear and coal units and a significant share of wind production in the North and East of Germany. The German transmission grid is well connected with the rest of Europe, and Germany is a net exporter of electrical energy.

Figure 1 shows the hourly demand distribution of the German market in January and February 2006 (net of wind production). We restrict our analysis to these two winter months as strategic behavior is more likely to occur when capacity is scarce. We limit our study period to two months as the SFE model assumes that the underlying cost structures remain constant for the duration of the bidding period. Taking a longer period would invalidate these underlying assumptions as plant availabilities, fuel prices and $\mathrm{CO}_{2}$ emission allowance prices change through time.

Most of the electricity in Germany is traded bilaterally, but voluntary power exchanges selling standardized products, are gaining importance. The main price index for Germany is the day ahead price at the European energy exchange (EEX). Figure 2 shows clearly that there are two distinct price ranges which correspond to off peak and peak periods. 


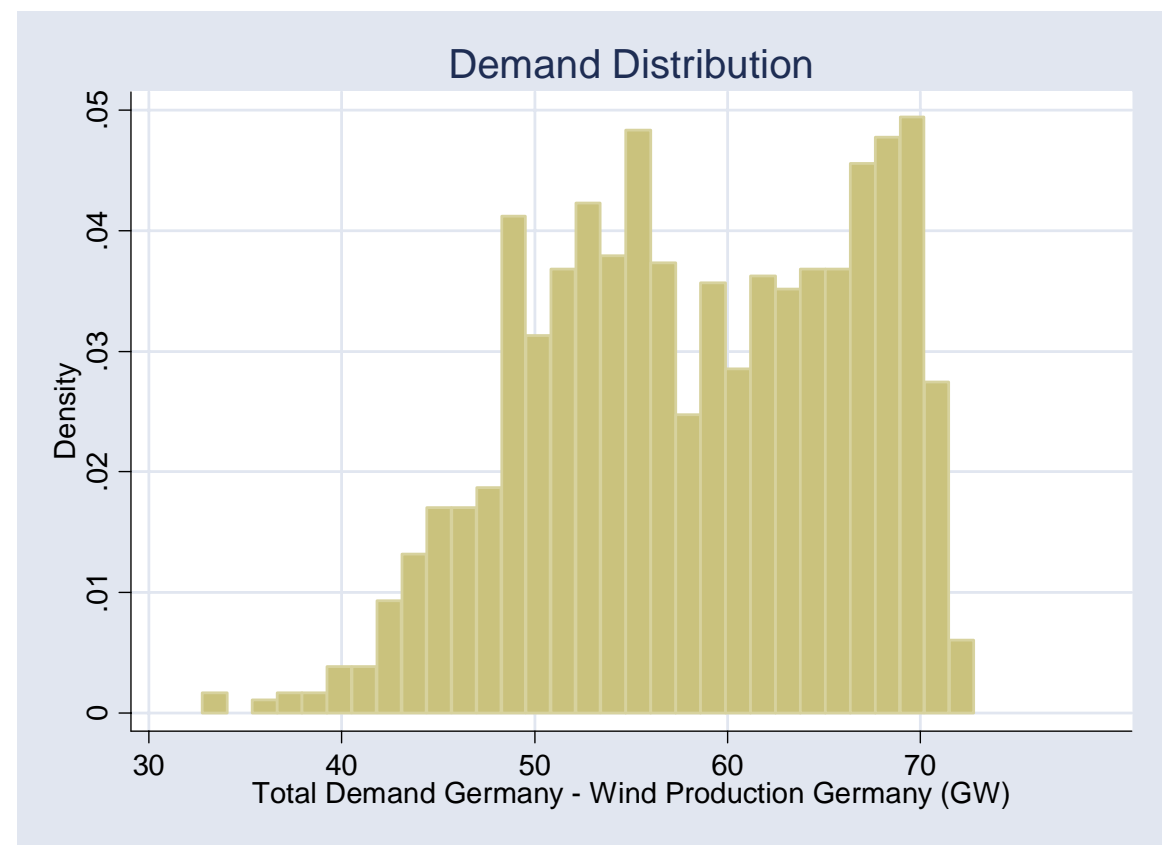

Figure 1 Germany Demand distribution Sources: UCTE (2007), Wind?

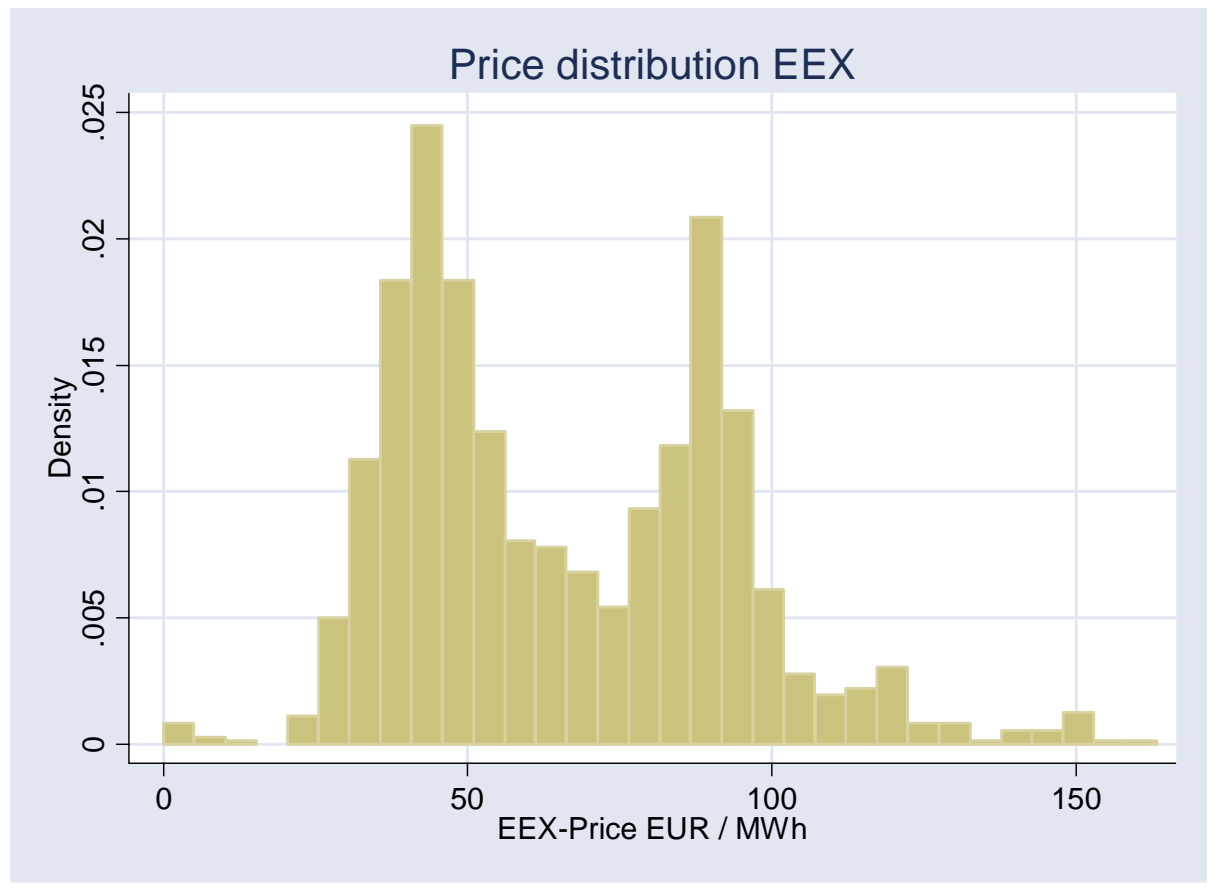

Figure 2 Price distribution on the EEX. 


\subsection{Approximation of the cost functions of the Generators}

The marginal costs of generator $i$ is described by a function $c_{i}(q)$, which takes into account the generation park of each player. Generation capacities and ownership are obtained from public sources, mainly VGE (2006). Generation capacities are decreased by seasonal availability factors following Hoster (1996). Using a type specific algorithm based on Schröter (2004) with construction year as proxy a plant specific efficiency is calculated and marginal costs are derived. Fuel prices are taken from Bafa (2006). Furthermore emission allowances are included by estimating $\mathrm{CO}_{2}$-emissions based on plant type and plant efficiency, allowance prices are taken from EEX.

In the model, the marginal cost functions of the generators are simplified to a cubic function.

$$
\tilde{c}_{i}(q)=\lambda_{i 0}+\lambda_{i 1} q+\lambda_{i 2} q^{2}+\lambda_{i 3} q^{3}
$$

where the parameters of the function are found by minimizing the weighted squared difference of the parameterized function and the true cost function, subject to the condition that marginal cost should be upward sloping. The following optimization problem is solved

$$
\begin{aligned}
& \min _{\lambda_{0}, ., \lambda_{3}} \int\left(\tilde{c}_{i}(q)-c_{i}(q)\right)^{2} d F(c(q)) \\
& \text { s.t. } \quad \tilde{c}_{i}{ }^{\prime}(q) \geq 0
\end{aligned}
$$

with $F(\cdot)$ the cumulative density function of the prices in the EEX power exchange. Figure 3 shows the approximate marginal cost function for the four largest players.

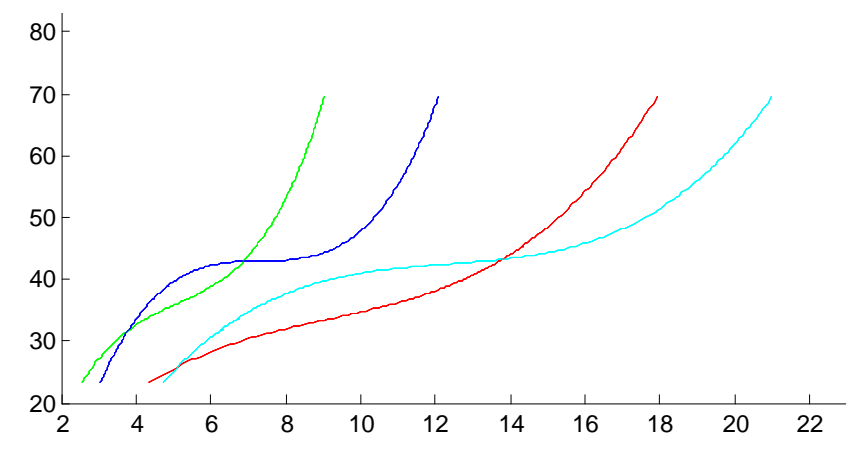

Figure 3: Competitive Supply Functions

\subsection{The demand function faced by the oligopolists}

This subsection derives the demand function that the four largest players in Germany face, which we will call the oligopolistic demand function $D^{O}$. The final demand $D$ for energy is served by 
wind production $Q_{W}$, by imports $Q_{I}$, by production of the four oligopolists in Germany $Q_{i}$ and by the fringe generator $Q_{F}$.

$$
D=Q_{W}+Q_{F}+Q_{I}+Q_{F}+\sum_{i=1}^{4} Q_{i}
$$

We assume that the demand for electricity $D$ does not depend on the price, but varies through time and has a random component. $D=\alpha_{t}^{D}+\varepsilon_{t}^{D}$. Wind production might also vary through time and has a random component too. $Q_{W}=\alpha_{t}^{W}+\varepsilon_{t}^{W}$. The production level of the fringe generators depends on the price they obtain for their output. The supply of the fringe is determined by the inverse of its marginal cost function.

$$
Q_{F}(p)=M C^{-1}(p)
$$

We approximate the marginal cost function linearly, and rewrite the supply function of the fringe as:

$$
Q_{F}(p)=\alpha_{F}+\gamma_{F} p
$$

Two approaches were used to determine the parameters $\alpha_{F}$ and $\gamma_{F}$. In the first one, we use a weighted least squares regression where we use the price density function of the EEX as weights. This approach typically underestimates the marginal cost for large prices. In the second approach we assume that the fringe is always producing at full capacity $\left(\gamma_{F}=0\right)$.

German imports are determined by the difference of the price in Germany and the neighboring regions. If the price in Germany is high relative to the price in neighboring regions, imports increase. We estimate imports by the following equation:

$$
Q_{I t}=\gamma_{I} p_{t}-\sum_{j} \gamma_{j} p_{j t}+\sum_{z} \beta_{z} \delta_{z t}+\varepsilon_{t}^{I}
$$

with $p_{t}$ the price in Germany, $p_{j t}$ the price in border country $j$, and $\delta_{z t}$ a vector of time dummies (day of week, and peak hours). ${ }^{8}$ A two-stage least squares estimator is used to address the endogeneity of the German price $p$ with respect to imports. As instruments we use the total demand level in Germany $D_{t}$ and German wind production $Q_{t}^{W}$. As explained in Bushnell et al.

\footnotetext{
${ }^{8}$ Hourly price data was used from the Netherlands, France, Austria, Poland, Sweden, East Denmark and West Denmark.
} 
(2005), the demand level is a valid instrument for import levels as demand is short-term inelastic, and does not depend on the price level in Germany.

Combining equations (15) to (18) we can rewrite the residual demand function for the oligopolists:

$$
D_{O}(p)=\alpha_{t}^{O}-\left(\gamma_{F}+\gamma_{I}\right) p_{t}+\varepsilon_{t}^{O}
$$

The oligpolists face an elastic demand function due to import elasticity and the supply of the fringe generators $\left(\gamma_{F}+\gamma_{I}\right)$. In the model, the demand shock $\alpha_{t}$ and the random component $\varepsilon_{t}$ are combined in a constant demand intercept $\alpha^{O}$ and a positive shock $\Delta$. We chose the intercept of the demand level such that, when the shock is zero, $90 \%$ of the observations in the German market are below the demand function. $10 \%$ of the outliers are not taken into account.

The demand elasticity which we obtain in the model is relatively large. An increase of the German electricity prices will increase the import levels and the production by the fringe generators. Our analysis does not take into account cross border capacity constraints and the production constraints of the fringe. We are therefore likely to overestimate elasticity in peak periods, and to underestimate elasticity in off-peak periods. ${ }^{9}$

\section{Outcome of the model}

Combining price data of the German power exchange, the demand, import and wind data, Figure 4 shows the aggregate supply function of German thermal production. The aim of this paper is to test whether a Cournot model or a SFE approach is capable to explain this observed aggregated supply function, taking into account the cost of the firms and strategic behavior of the four largest generation firms.

\footnotetext{
${ }^{9}$ This implies that our model is likely to predict too low prices in the peak period and too high prices in the off-peak hours.
} 


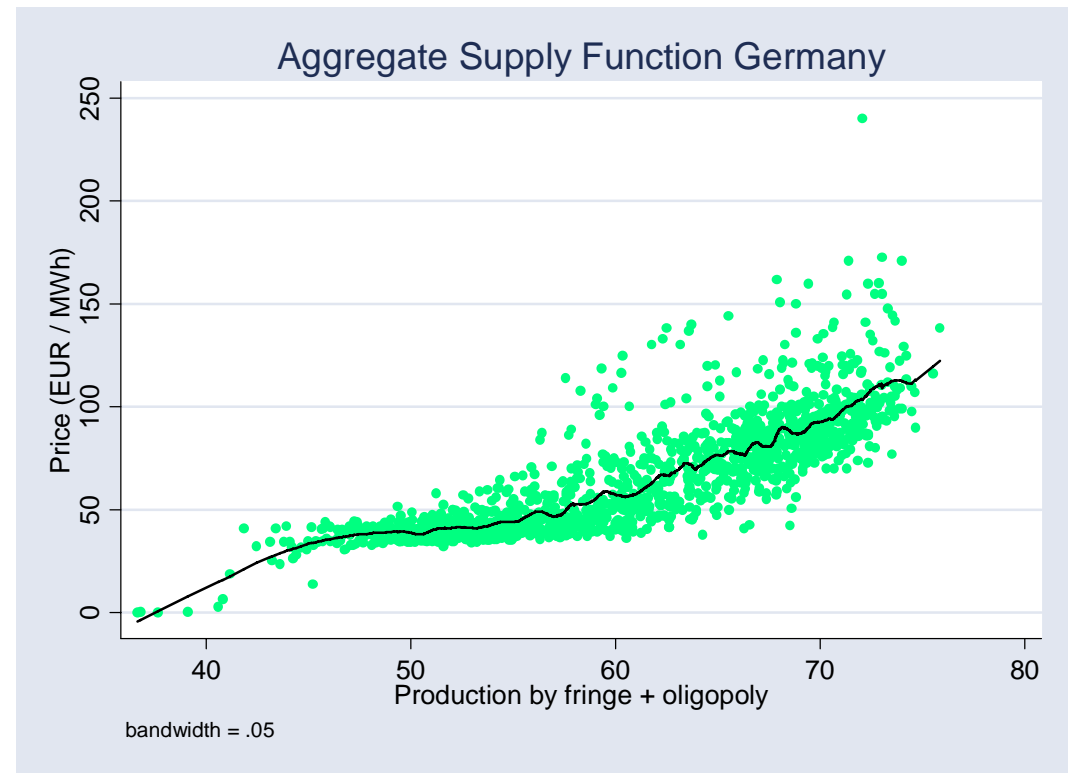

Figure 4: Aggregate supply function of the Oligopolists and the Fringe Generator

As the exact properties of the market are normally not publicly available and simplifications are necessary due to computation restrictions, we allow for several adjustments to fit the modeled outcomes to the observed price quantity combinations (Table 1). For the behavior of the fringe we consider two cases: one where the fringe has an elastic supply function and one where the fringe is always producing at full capacity, as explained above. The elastic supply function is on average the best representation of the supply of the fringe generator, but neglects capacity constraints. The inelastic supply function might be a better representation of the supply by the fringe during peak periods when capacity constraints play a larger role. We look at two scenarios with respect to the fixed capacity contracts. In the base case, firms have no fixed capacity contracts $f=0$. In the alternative scenarios, firms have contracted $30 \%$ of their installed capacity: $f_{i}=0.3 \cdot q_{i}^{\text {cap }}$, with $q_{i}^{\text {cap }}$ the installed capacity of player $i$. 


\begin{tabular}{|lr|}
\hline Elasticity of the Fringe & $\gamma_{F}$ \\
$\quad$ Fringe, always producing at full capacity & 0.0000 \\
Elastic, price responsive fringe & 0.0947 \\
\hline Fixed capacity contracts & $f / q_{i}^{\text {cap }}$ \\
$\quad$ Firms have no fixed capacity contracts & $0 \%$ \\
$\quad \begin{array}{l}\text { Firms have signed a fraction of their total production } \\
\text { capacity }\end{array}$ & $30 \%$ \\
\hline Supply Function Equilibruim Model & \\
$\quad \begin{array}{l}\text { A set of equilibrium supply functions: ranging from very } \\
\text { competitive to less competitive }\end{array}$ & \\
\hline Cournot Model & \\
$\quad$ Equilibrium function is calculated for different \\
percentages of load following contracts
\end{tabular}

Table 1 Assumptions of the model

For the Cournot model different amounts of load following contracts are assumed. By varying the load-following contract cover $\phi_{i}$ over the range $0-100 \%$, a bundle of equilibrium supply functions is obtained similar to the SFE outcome. The highest Cournot supply describes the standard Cournot outcome, where there is no contract cover, and the lowest one describes the Cournot outcome with full contract cover (the competitive equilibrium). The SFE-model gives a bundle of equilibria. Which equilibrium firms chose depends on how these firms co-ordinate.

Both the SFE and the Cournot model produce a large set of feasible solutions, depending on assumptions taken. To test which models predicts the market outcomes more realistically, the observed price-demand results during January and February 2006 are taken as a benchmark. In order to compare the model prices with the prices observed in the market, we will calculate the Rsquared coefficient. The R-squared is a measure of how much of the variation in observed prices is explained by the model:

$$
R=1-\frac{\sum_{t}\left(P_{t}-\tilde{P}_{t}\right)^{2}}{\sum_{t}\left(P_{t}-\bar{P}\right)^{2}}
$$

with $\bar{P}$ the average observed price on the market and $\tilde{P}_{t}$ is the prediction of the model. As the model does not contain a "constant" calibration term, the model might be wrong in expected terms, $E\left(\tilde{P}_{t}\right) \neq \bar{P}_{t}$ and we might observe negative R-squared. Roughly speaking, negative numbers imply that the average price which is observed on the market is a better predictor than the price predicted by the model. 
The model predictions $\tilde{P}_{t}$ can be calculated in several ways. Here, we will concentrate on a definition which makes the R-squared informative on how well the model explains the supply side of the model while neglecting errors on the demand side: ${ }^{10}$

Assume that in period $k$ the demand shock is $\Delta_{k}$, and that each player $i$ bids according to its optimal strategy $q_{i k}^{\text {opt }}$, but that its actions are perturbed with a random error $\varepsilon_{i k}$. The observed production level in the market is then:

$$
q_{i k}^{o b s}=q_{i k}^{o p t}+\varepsilon_{i k}
$$

which gives the following aggregate production level

$$
D_{k}^{O, o b s}=D_{k}^{O, o p t}+\sum_{i} \varepsilon_{i k}
$$

and market clearing price :

$$
p_{k}^{o b s}=p_{k}^{o p t}-\frac{1}{\gamma} \sum_{i} \varepsilon_{i k}
$$

We are interested in finding a measure of the bidding error $\varepsilon_{i k}$ of the players. Equation (23) shows that the bidding error of the players can be found by looking at the difference of the observed prices and the optimal prices as predicted by the model, evaluated for the same demand shock $k$. These error terms measure the errors in the supply function model, conditional on the demand functions being perfectly defined.

Table 2 gives the R-squared for the Cournot models, as a function of the number of contracts signed by the incumbent and supply elasticity of the Fringe. The model results indicate that the behavior in the market can be best described by a Cournot model where the generators have

${ }^{10}$ An alternative way to calculate a price prediction is by interpolating the aggregate supply function of the model for the observed demand level $D_{t}$. The problem with this approach is that the supply functions in the SFE model are only defined as long as the demand level is smaller than the capacity $D_{\text {max }}$, at which point the supply function becomes perfectly inelastic. Extrapolating the data of the model for larger capacities would gives infinite prices and R would become minus infinite. Such a measure is not very informative. We could also drop observations when demand is larger than $D_{\max }$, but this boundary depends on the equilibrium we select, and might therefore distort the results. Another drawback is that it both measures errors in demand and supply. 
contracted a certain percentage of their production capacity ex-ante, and a relatively low amount of load following contracts. The model which fits the data best has an R-squared of 0.825 , and assumes that the firms have sold $30 \%$ of their production capacity forward, have covered $22 \%$ of the remainder of the capacity with load-following contracts and fringe supply is inelastic. The effect of this $30 \%$ capacity contracts is that market power will be more pronounced during high demand periods, and that markets are more competitive during periods with low demand. This reflects the empirical observation that mark-ups are higher during peak periods (Figure 5). The load-following contracts do not change the shape of the supply function, but determine the markup that players take. Higher contract factors lead to lower prices for the generators. The assumption of a fixed supply by the fringe generator has two effects (1) The aggregate marginal cost function of the German industry changes. It is shifted to the right (as the fringe operates as if it had zero production costs), and it becomes steeper for higher levels of production. (2) The oligopolists face a less elastic demand, as demand responsiveness is only provided by imports and not by the fringe, and have an incentive to set higher prices.

\begin{tabular}{|c|c|c|c|c|c|c|c|c|c|c|c|}
\hline \multirow[t]{2}{*}{$\gamma_{F}$} & \multirow{2}{*}{$\begin{array}{r}\text { contracted } \\
\text { capacity }\end{array}$} & \multirow{2}{*}{$\begin{array}{l}\text { Compet. } \\
100 \%\end{array}$} & \multicolumn{7}{|c|}{ Percentage Contracting } & \multicolumn{2}{|c|}{ Cournot 0} \\
\hline & & & $89 \%$ & $78 \%$ & $67 \%$ & $56 \%$ & $44 \%$ & $33 \%$ & $22 \%$ & $11 \%$ & $\%$ \\
\hline 0.0947 & $0 \%$ & 0.183 & 0.405 & 0.552 & 0.627 & 0.638 & 0.591 & 0.493 & 0.351 & 0.171 & -0.043 \\
\hline 0.0947 & $30 \%$ & 0.183 & 0.325 & 0.443 & 0.539 & 0.614 & 0.670 & 0.709 & 0.733 & 0.744 & 0.742 \\
\hline 0.0000 & $0 \%$ & -0.208 & 0.306 & 0.597 & 0.692 & 0.618 & 0.402 & 0.065 & -0.374 & -0.899 & -1.498 \\
\hline 0.0000 & $30 \%$ & -0.208 & 0.097 & 0.338 & 0.524 & 0.659 & 0.750 & 0.804 & 0.825 & 0.816 & 0.783 \\
\hline
\end{tabular}

Table 2 R-squared of Cournot models with different contracting levels 


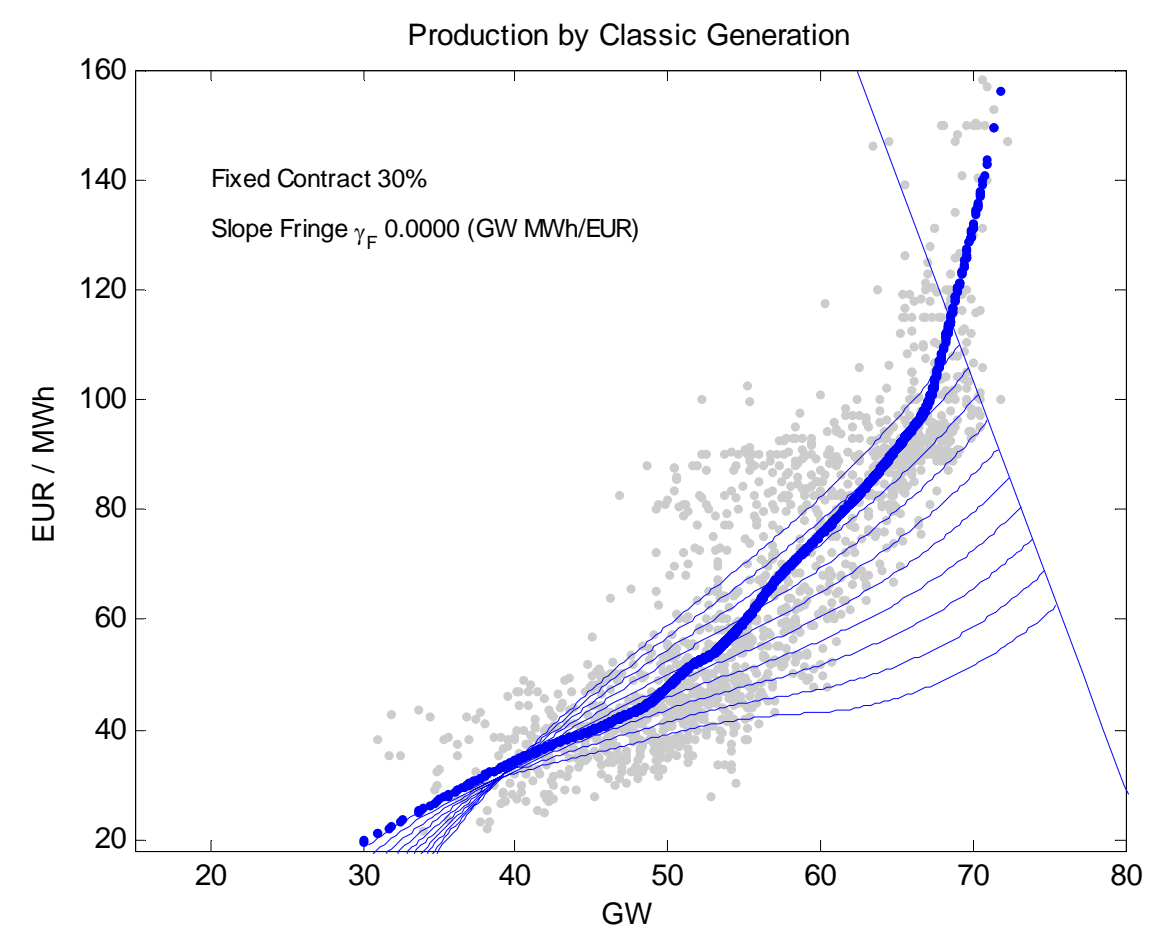

Figure 5: Cournot outcome with fixed fringe supply and 30\% fixed contracts

Table 3 describes the R-squared for the Supply function equilibrium. Given that the shape of the Supply function equilibrium reflects the shape of the empirical supply function better, most of the R-squared variables are rather high. The fixed capacity contracts reduce the fit of the SFE model. The reason for this is that it predicts too low prices. The SFE model which fits the data best, is the one where the supply of the fringe is inelastic, the firms did not sign any contracts, and players co-ordinate on an average priced equilibrium supply function. The R-squared becomes 0.836 . (Figure 6)

Comparing the outcomes to the lowess estimation of the observed supply function ${ }^{11}$ shows a good fit in peak and mid load times. During off-peak periods prices of the SFE model are above EEX prices.

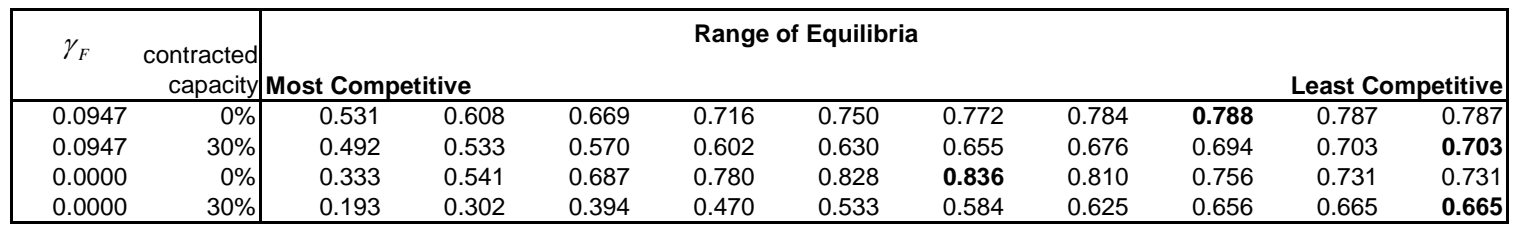

Table 3 R-squared of SFE-models for the different scenarios

${ }^{11}$ LOWESS is a local regression using weighted linear least squares and a $1^{\text {st }}$ degree polynomial model. 


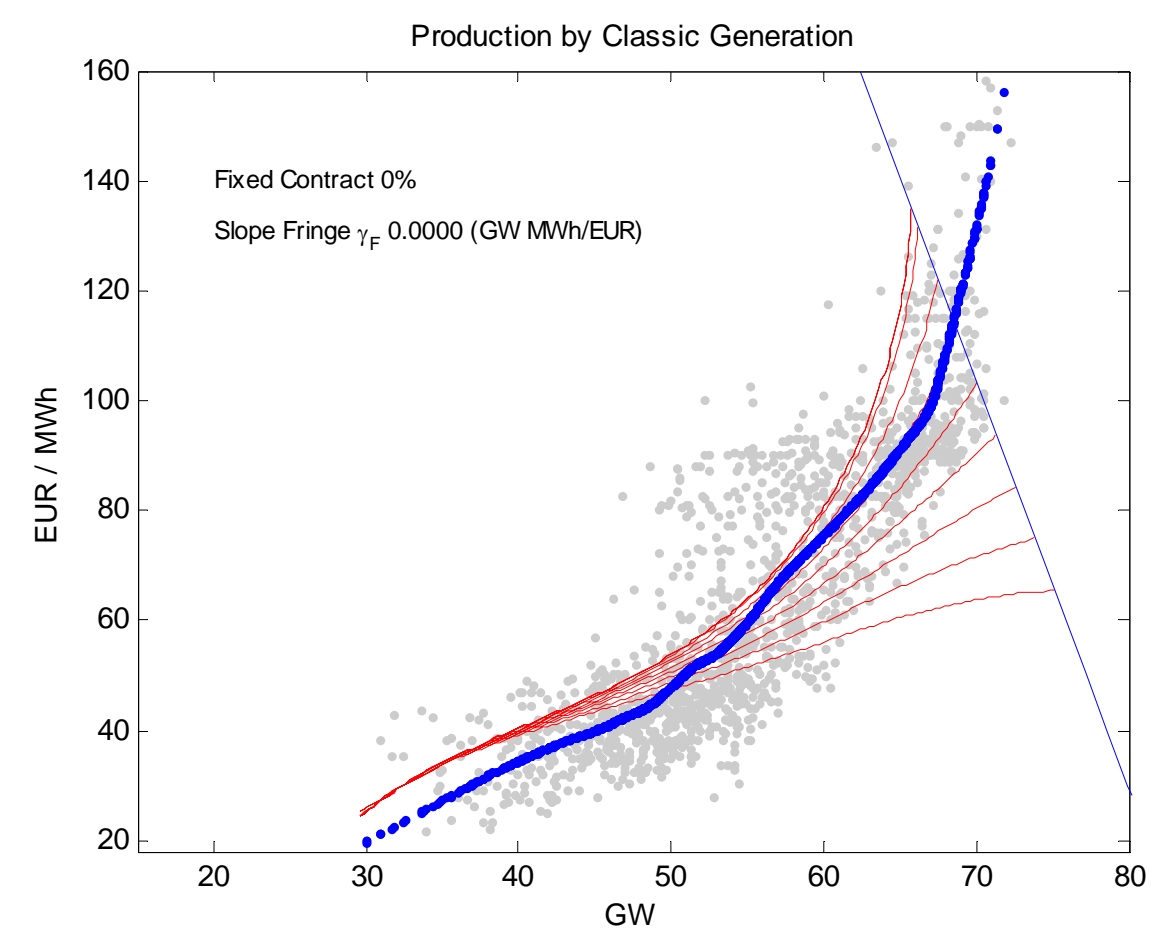

Figure 6: SFE outcome with fixed fringe supply and without fixed contracts

Comparing the SFE and the Cournot model, we observe that once the models are calibrated, they perform equally well. The range of equilibrium outcomes under the SFE model is smaller than in the Cournot case, which is reflected in a smaller variation in R-squared.

\section{Conclusion}

This paper compares the classical Cournot model with the SFE approach to test whether the higher complexity of SFE results in a better representation of strategic market outcomes. Both models are tested using the same database of the German electricity market and the same assumptions regarding demand and generation. The modeling results are then compared to observed market outcomes. We calibrate the model by changing the amount of fixed capacity and load-following contracts that firms sign, the behavior of the fringe, and by changing the equilibrium on which firms co-ordinate in the SFE model.

The results indicate that the Cournot approach can be calibrated well to the observed market outcomes by assuming 30\% fixed capacity contracts and a relatively low level of load following contracts. For the SFE model, the best fit is found in the case where firms do not sell fixed capacity contracts, coordinate on intermediate price levels, and the fringe generator has an 
inelastic supply. Using the R-squared coefficient as a measure, the calibrated SFE and Cournot models perform equally well: they explain the same percentage of the price variation in the market. We conclude therefore that the SFE-model does not significantly outperform the Cournot model as a tool to study the German electricity market. The SFE-models rely, however, less on calibration parameters than the Cournot model, and seem therefore to give more robust predictions.

In order to solve the models numerically, especially the SFE-model, several simplifying assumptions were made with respect to the generation and demand data. The simplifying assumptions might bias the quantitative and qualitative results of the model. The linearization of import and fringe behavior can lead to a general over-estimation of demand elasticity especially for high demand periods resulting in too low prices in the wholesale market. The neglecting of start-up and ramping issues leads to an overestimation of costs during off peak periods. The general assumption of continuous supply function may lead to an underestimation of generation costs close to peak capacity.

We do not know whether our results extend to other electricity markets, but we conjecture that the difference between the SFE-model and the Cournot model will become less pronounced as markets become less concentrated and more dependent on imports. In the limit, with competitive markets, the SFE and the Cournot model give identical results. However, for markets which are less import dependent and more concentrated than Germany, the SFE might give better results than Cournot.

Given the currently limited flexibility of SFE approaches to incorporate technical characteristics as unit commitment, start-up costs and network issues Cournot models are the preferred option when electricity markets need to be modeled in detail. Thus Cournot models are suited for the study of market rules, or congestion allocation mechanisms. However, when long term aspects play a role, for instance in a merger study, SFE-models might become more relevant as they are less sensitive with respect to calibration parameters than Cournot models. Furthermore, for longterm simulations, one cannot assume that contract positions are exogenous, increasing the complexity of Cournot models.

\section{References}

Allaz, Blaise, und Jean-Luc Vila (1991): Cournot Competition, Forward Markets and Efficiency. Journal of Economic Theory, Vol. 59, No. 1, pp. 1-16. 
Anderson, Edward J and Xinmin $\mathrm{Hu}$ (2005): Finding Supply Function Equilibria with Asymmetric Firms. Mimeo. Australian Graduate School of Management.

Bafa (2006): http://www.bafa.de/1/de/aufgaben/energie/, retrieved 21.08.06.

Baldick, Ross and William Hogan (2002): Capacity Constrained Supply Function Equilibrium Models of Electricity Markets: Stability, Non-decreasing constraints, and Function Space Iterations. Working Paper PWP -089, University of California Energy Institute.

R. Baldick, R. Grant and E. Kahn (2004), "Theory and Application of Linear Supply Function Equilibrium in Electricity Markets", Journal of Regulatory Economics, Vol.25, No. 2, pp. $143-167$.

Boisseleau, François, Kristiansen Tarjei, Petrov Konstantin, and Wim van der Veen (2004): A Supply Function Equilibrium Model with Forward Contracts - An Application to Wholesale Electricity Markets, IAEE conference proceedings, Zurich.

Bolle, Friedel (1992): Supply Function equilibria and the danger of tacit collusion. The case of spot markets for electricity. Energy Economics, Vol. 14, No. 2, pp. 94-102.

Borenstein, Severin, Jim Bushnell, Christopher Knittel (1999): Market Power in Electricity Markets: Beyond Concentration Measures. Energy Journal, Vol. 20, No.4.

Brandts, Jordi, Paul Pezanis-Christou, and Arthur Schram (2003): Competition with Forward Contracts: A Laboratory Analysis Motivated by Electricity Market Design. Unitat de Fonaments de l'Anàlisi Econòmica (UAB) and Institut d'Anàlisi Econòmica (CSIC).

Bushnell, James, Christopher Day, Max Duckworth, et al. (1999): An International Comparison of Models for Measuring Market Power in Electricity. Stanford University, EMF Working Paper 17.1, Energy Modeling Forum.

Bushnell, James, Erin Mansur, und Celeste Saravia (2005): Vertical Arrangements, Market Structure, and Competition: An Analysis of Restructured U.S. Electricity Markets. CSEM WP 126, University of California Energy Institute.

Ciarreta, Aitor, and Carlos Gutierrez-Hita (2006): Supply function vs. quantity competition in supergames. In: International Journal of Industrial Organization, Vol. 24, pp. 773- 783.

Day, Christopher, Benjamin Hobbs, and Jong-Shi Pang (2002), Oligopolistic competition in power networks: a conjectured supply function approach. IEEE Transactions on Power Systems Vol. 17, No. 3, pp. 597-607.

Delgado, Juan and Diego Moreno (2004), Coalition-proof supply function equilibria in oligopoly. Journal of Economic Theory, Vol. 114 pp. 231-254. 
Ellersdorfer, Ingo (2005): A Multi-Regional Two-Stage Cournot Model for Analyzing Competition in the German Electricity Market. IAEE European Conference 2005.

Evans, Joanne and Richard Green (2005): Why did British electricity prices fall after 1998? Economic and Social Research Council project. University of Surrey and University of Birmingham.

Green, Richard J. and David M. Newbery (1992): Competition in the British Electricity Spot Market. Journal of Political Economy, Vol. 100, No. 5, pp. 929-953.

Green, Richard J. (1996): Increasing Competition in the British Electricity Market, Journal of Industrial Economics Vol. 44, pp. 205-216.

Holmberg, Pär (2005): Asymmetric Supply Function Equilibrium with Constant Marginal Costs. Uppsala Universitet. Department of Economics, Working Paper 2005:16.

Holmberg, Pär (2006): Unique supply function equilibrium with capacity constraints. Uppsala Universitet. Energy Economics, forthcoming.

Hoster, Frank (1996): Auswirkungen des europäischen Binnenmarktes für Energie auf die deutsche Elektrizitätswirtschaft. Oldenbourg, München.

Hu, Xinmin, Daniel Ralph, Eric K. Ralph, Peter Bardsley, and Michael C. Ferris (2004): Electricity generation with looped transmission networks: Bidding to an ISO. CWPE 0470, University of Cambridge, Cambridge Working Papers in Economics.

Klemperer, Paul D. and Margaret A. Meyer (1989): Supply Function Equilibria in Oligopoly und Uncertainty. Econometrica, Vol. 57, No. 6, pp. 1243-1277.

Rudkevich, A. (2005). On the supply function equilibrium and its applications in electricity markets, Decision Support Systems, Vol. 40. pp. 409-425.

Schröter, Jochen (2004): Auswirkungen des europäischen Emissionshandelssystems auf den Kraftwerkseinsatz in Deutschland. Diplomarbeit, Berlin University of Technology, Institute of Power Engineering.

Sioshansi, R. and S. Oren (2007) How Good are Supply Function Equilibrium Models: An Empirical Analysis of the ERCOT Balancing Market. Journal of Regulatory Economics, Vol. 31, No. 1, pp 1-35.

Smeers, Y. and J. Wei (1997): Spatially oligolpolist models with opportunity cost pricing for transmission capacity reservations - A variational approach. Core discussion papers 9717. 
Twomey, Paul, Richard Green, Karsten Neuhoff, und David Newbery (2004): A Review of the Monitoring of Market Power. CWPE 0504, University of Cambridge, Cambridge Working Papers in Economics.

Ventosa, Mariano, Baíllo, Álvaro, Ramos, Andrés and Michel Rivier (2005): Electricity market modeling trends. Energy Policy, Vol. 33, pp.897-913.

Vives, Xavier (2007): Strategic Supply Function Competition with Private Information. Presentation at the Toulouse Energy Conference, January 2007.

VGE (2006): Jahrbuch der europäischen Energie- und Rohstoffwirtschaft 2006. Essen, Verlag Glückauf GmbH.

Wächter, A. and L. T. Biegler, (2006) On the Implementation of a Primal-Dual Interior Point Filter Line Search Algorithm for Large-Scale Nonlinear Programming, Mathematical Programming 106(1), pp. 25-57,

Willems, Bert (2002): Modeling Cournot Competition in an Electricity Market with Transmission Constraints. Energy Journal, Vol. 23, No. 2. pp. 95-125. 


\section{Appendix}

Table 4 present the results of the regression (18) for two different formulations. The regression shows that German imports are significantly correlated with energy prices in France, the Netherlands, Austria and East Denmark, while the impact of Sweden, Poland and West Denmark is weaker. This can be explained by the fact that the Swedish and the West Denmark market are not strongly integrated with the German market, and that the Polish market is still being developed. France is a net exporter of electrical energy and a main factor in all European markets. The Netherlands is a net importer of electrical energy and depends heavily on imports from Germany and France to balance its system. As there are also Dutch-German and French-German cross border companies, we expect these markets to be relatively well integrated.

\begin{tabular}{|c|c|c|c|c|}
\hline $\begin{array}{l}\text { Instrum. } \\
\mathrm{N}\end{array}$ & \multicolumn{2}{|c|}{$\begin{array}{l}\text { IV } 1 \\
\text { Wind, Production } \\
\quad 1416\end{array}$} & \multicolumn{2}{|c|}{$\begin{array}{l}\text { IV } 2 \\
\text { Wind, Production } \\
\quad 1416\end{array}$} \\
\hline import & Coef. & & Co & \\
\hline ex & 134.6381 ** & 5.87 & $129.1448^{* \star}$ & 6.1 \\
\hline apx & -14.4745 ** & -3.5 & $-14.1845^{* *}$ & -3.56 \\
\hline france & -40.8166 ** & -6.9 & $-41.8347^{* \star}$ & -7.23 \\
\hline austria & -59.7796 ** & -3.2 & $-58.8117^{* *}$ & -3.3 \\
\hline poland & -8.02858 & -1.2 & ** & \\
\hline dkeast & $-13.6628 * *$ & -2.9 & $-12.1619 * *$ & -2.78 \\
\hline dkwest & -14.5495 & -1.1 & ** & \\
\hline sweden & 21.60157 & 1.8 & ** & \\
\hline cons & -2582.67 ** & -3.2 & -3016.11 ** & -11.66 \\
\hline day_1 & 925.4917 ** & 2.76 & $993.0198 * *$ & 3.14 \\
\hline day_2 & $701.1942 *$ & 2.13 & 779.691 * & 2.49 \\
\hline day_3 & $661.7167^{*}$ & 2.03 & 691.4439* & 2.21 \\
\hline day_4 & 295.2127 & 0.79 & 390.4124 & 1.11 \\
\hline day_5 & 486.488 & 1.45 & 575.7134 & 1.81 \\
\hline day_6 & 308.389 & 1.04 & 293.6928 & 1.0 \\
\hline Peak & -160.576 & -0.7 & -172.905 & -0.7 \\
\hline
\end{tabular}

Table 4: Import regression, **: Significant at 99\% level, * significant at 5\% level. 


$\begin{array}{lrrcc} & \lambda_{0} & \lambda_{1} & \lambda_{2} & \lambda_{3} \\ \text { firm1 } & -6.42199 & 10.46086 & -0.99737 & 0.03625 \\ \text { firm2 } & -25.7214 & 31.02555 & -5.57416 & 0.36578 \\ \text { firm3 } & -30.06226 & 16.7424 & -1.32019 & 0.03564 \\ \text { firm4 } & -54.26723 & 39.52206 & -5.36787 & 0.24364\end{array}$

Table 5: Coefficients of the cubic marginal cost functions

Supply function of importers:

$$
Q=A+0.1346381 P
$$

Supply function of the elastic fringe

$$
Q_{F}=6.9718+.0947 P
$$

Supply function of the inelastic fringe

$$
Q_{F}=17.9300
$$

Demand function for the Oligopolists (Elastic Fringe).

$$
D^{O}=76-0.2293 P-\Delta
$$

Demand function for the Oligopolists (Inelastic Fringe).

$$
D^{O}=66-0.1346 P-\Delta
$$


Copyright (c) 2007 @ the author(s). Discussion papers are in draft form. This discussion paper is distributed for purposes of comment and discussion only. It may not be reproduced without permission of the copyright holder. Copies of working papers are available from the author. 